\title{
O PROGRAMA VILAS OLÍMPICAS NA CIDADE DO RIO DE JANEIRO NO PERÍODO 2000-2009: A GESTÃO POR ORGANISMOS DO CHAMADO TERCEIRO SETOR ANTES DA LEI DAS OSs (LEI 5026/2009)
}

\author{
THE OLYMPIC VILLAGES PROGRAM IN RIO DE JANEIRO IN 2000-2009: ITS \\ MANAGEMENT BY SO-CALLED THIRD SECTOR ORGANIZATIONS BEFORE \\ THE LAW SOCIAL ORGANIZATIONS (5026-2009)
}

EL PROGRAMA VILLAS OLÍMPICAS EN LA CIUDAD DE RIO DE JANEIRO EN EL PERÍODO 2000 A 2009: LA GESTIÓN POR ORGANISMOS DEL LLAMADO TERCER SECTOR ANTES DE LA LEY DE LAS OSs (LEY 5026-2009)

Marcelo Paula Melo*

Palavras chave:

Esportes.

Política pública.

Controles formais da sociedade.
Resumo: O programa Vilas Olímpicas da Prefeitura do Rio de Janeiro teve início em 2000, pautado nos pressupostos da reforma do Estado neoliberal já em curso no Brasil. Sua administração nunca foi diretamente da Prefeitura do Rio de Janeiro (PMRJ), contando com federações esportivas e ONGs na gestão e contratação de pessoal. Tal processo não foi isento de contradições, como mostram documentos do Tribunal de Contas do Município. O objetivo deste texto foi analisar as contradições da relação entre Estado e sociedade civil na execução de políticas sociais de esporte como parte do processo de privatização e precarização da ação estatal. Este texto mostra que tal relação com organismos na sociedade civil foi anterior à legislação específica das organizações sociais em 2009, acompanhando o programa da PMRJ desde sua fundação.
Keywords:

Sports.

Public policy. Formal controls of society.
Abstract: Rio de Janeiro city government's Olympic Villages program began in 2000, based on assumptions of neoliberal state reform already under way in Brazil. It has never been directly managed by the city government. Sports federations and NGOs did personnel management and hiring. The process saw its contradictions as shown by documents of the City's Accounting Control Agency. This paper looked into contradictions in the State's relations with and civil society regarding implementation of social policies for sport as part of the process of privatization and precarization of state action. This text shows that such relations with civil society organizations existed before the law regulating those organizations was passed by 2009 , following the city government's program since its foundation.

Palabras clave: Deportes.

Política pública. Controles formales de la sociedad.
Resumen: El programa Villa Olímpica de la Municipalidad de Rio de Janeiro comenzó en el año 2000, en base a los supuestos de la reforma del Estado neoliberal ya en marcha en Brasil. Su administración nunca fue directamente de la Municipalidad de Rio de Janeiro, sino que contó con las federaciones deportivas y ONGs en la gestión y para contratar personal. Este proceso no estuvo exento de contradicciones, como muestran documentos del Tribunal de Cuentas del Municipio. El objetivo de este trabajo fue analizar las contradicciones en la relación entre Estado y sociedad civil en la ejecución de políticas sociales de deporte como parte del proceso de privatización y precarización de la acción del Estado. Este texto muestra que tal relación con organismos en la sociedad civil fue anterior a la actual legislación específica de las organizaciones sociales en 2009, acompañando el programa desde su fundación.
*Universidade Federal do Rio de Janeiro. Rio de Janeiro, RJ, Brasil. E-mail: marcelaomelo@gmail.com

Recebido em: 02-09-2016 Aprovado em: 09-08-2017

$\mathrm{DOl}:$ http://dx.doi.org/10.22456/1982-8918.67552 (c) (1) (8) Licence 


\section{INTRODUÇÃO}

Este texto debate a gestão do programa Vilas Olímpicas, da Prefeitura Municipal do Rio de Janeiro (PMRJ), sobretudo, no tocante à relação Estado e sociedade civil. Esse programa inicia em 2000, e a gestão das unidades se deu a partir de relações jurídicas entre a PMRJ e uma série de organismos na sociedade civil, como federações esportivas, universidades privadas sob a forma de associações sem fins de lucro, além de organizações não governamentais clássicas. O período em tela abarca o final da administração Luiz Paulo Conde (1996-2000, PFL/DEM-PTB), integralmente a segunda e terceira gestões Cesar Maia (2001-2008, PFL/ DEM) - que havia sido prefeito de 1993-1996 - e $01^{\circ}$ ano da gestão de Eduardo Paes (20092016, PMDB). Em maio de 2009, é aprovada a lei 5026 e promulgado o decreto 30780, que regulamentam as relações entre a PMRJ e organizações sociais. Neste texto mostraremos que essa relação - e suas contradições em termos de má administração e precarização das políticas sociais de diversas ordens - antecede à referida legislação.

Sendo saudada como um retrato da (suposta) modernização da ação estatal, a delegação da execução de políticas sociais por organismos privados é um dos aspectos centrais do projeto de Reforma do Estado neoliberal (MELO, 2011; FONTES, 2010), posta em prática em diversos países. Analisar elementos concretos que contradigam a vulgata propagandística de uma suposta eficiência naturalizada dos organismos na sociedade civil como executores de políticas sociais (BRASIL, 1995; IOSCHOPE, 1996) pode lançar luz sobre esse resistente elemento do projeto neoliberal, que segue em vigor no Brasil.

Expressamente, a partir dos dados trazidos, pretendemos responder as seguintes indagações:

a) Quais exemplos de má gestão expressam as contradições na relação Estado e organismos na sociedade civil no âmbito do programa Vilas Olímpicas na cidade do Rio de Janeiro de 2000 a 2009? Como tais pontos aproximam-se dos estudos críticos sobre esse tipo de relação Estado e sociedade civil como expressão do projeto neoliberal?

b) Por que, mesmo com tais apontamentos fáticos, diversos órgãos, como Tribunal de Contas do Município, legislativo e executivo municipal do Rio de Janeiro envidaram esforços na aprovação de legislação, Lei 5026/2009, de sistematização e aprofundamento desse mecanismo de relação do executivo com organismos supostamente sem fins de lucro na execução de políticas sociais?

As fontes principais de dados serão diversos relatórios do Tribunal de Contas do Município (TCM) dispostos no período, a pesquisa de mestrado de Melo (2005), além de algumas reportagens de jornais sobre as Vilas Olímpicas e as entidades privadas que as geriam (e seguiram gerindo) no período anterior à lei das Organizações Sociais em 2009, aprovada em maio daquele ano.

\section{A PRIVATIZAÇÃO DAS POLÍTICAS SOCIAIS VIA TERCEIRO SETOR}

A análise do impacto das entidades do chamado terceiro setor - termo vulgar para expressar organismos na sociedade civil, que seriam distintos das empresas (segundo setor) e as entidades estatais (primeiro setor) (MELO, 2011; FONTES, 2010) - na vida social precisa incluir seu papel político e econômico. Como empregadores de larga escala de força de trabalho 
(MELO, 2015), torna-se inegável o impacto para imenso contingente da população brasileira que obtém sua existência na condição de funcionários desses organismos.

A emergência de um conjunto de organismos na sociedade civil criados com fito de estabelecer relações com órgãos estatais na prestação de serviços públicos de diversas naturezas atesta a preocupação do bloco no poder em garantir constantemente o consenso ativo dos trabalhadores. Sejam atendidos em programas executados por organismos na sociedade civil - ainda que financiados pelo Fundo público - ou na condição de trabalhadores desses organismos, as premências materiais mais básicas contribuem para aumentar a adesão à lógica de atuação estatal cara ao projeto neoliberal e geram mais barreiras a sua crítica radical.

Como afirma Paoli (2007), o que chama de invenção política e constituição organizada das reivindicações é obstado não somente pela repressão do bloco no poder, mas também pela transformação e domesticação de movimentos sociais contestatórios via mecanismos de aproximação com os governos através de programas de gestão da pobreza com a chamada participação da comunidade.

As novas expressões da relação público-privado ou estatal-civil como soma de interesses (supostamente) convergentes, até mesmo eliminando a possibilidade de divergência e antagonismos de projetos e concepções de mundo, implicam uma pedagogia contraditória. Assim, a dita promoção da cidadania, tão em voga em pronunciamentos de sujeito políticos radicados com interesses dos mais díspares possíveis, é louvada como algo não político ou mesmo apolítico, implicando em programas estatais ou privados de "[...] socorro ou prevenção do transbordamento dos problemas sociais" (PAOLI, 2013, p. 232).

A realização das atividades de um conjunto de organizações na sociedade civil conhecidas como ONGs - mas que são associações ou fundações voltadas à prestação de uma série de políticas sociais em campos variados - obrigatoriamente implica submissão:

\section{[...] a uma conciliação com os imperativos mercantis, financeiros e estatais, dentro dos quais a noção de 'público' se torna bastante elástica. Da mesma forma, impedem que a população receptora dos bens resultantes de tais práticas elabore qualquer outra compreensão desses atos para muito além do tradicional modo heteronômico de entender o gesto doador de salvação - ainda quando participem consensualmente (ou talvez em razão disso) de sua efetivação (PAOLI, 2007, p. 232).}

Mesmo em casos que haja resultados positivos e a total das melhores intenções, assim como uma atuação comprometida com o público atendido, a impossibilidade de problematização e questionamento radical - seja pela necessidade de existência coletiva da instituição ou individual dos trabalhadores - das manifestações contraditórias de financiadores e/ou membros governamentais tende a implicar uma cumplicidade com o status quo. Repetindo que isso não necessariamente se dará sempre por adesão ao projeto dominante, mas sim pela necessidade de manutenção da existência. Por isso a luta pela ação estatal impessoal e que não esteja atrelada diretamente ao bloco no poder por meio de servidores de carreira pode ser um passo importante - certamente não suficiente - de enfrentamento à lógica que funda a nova pedagogia da hegemonia burguesa.

$\mathrm{O}$ apelo dominante a ditos princípios éticos geralmente associados à cidadania e eficácia das ações implementadas por organizações privadas contribui fortemente para um quadro em que há uma confusão deliberada de noções. Isso implica que a naturalização da gestão de recursos públicos por organizações privadas na prestação de serviços que deveriam 
ser estatais - seja concessão de estradas e outras unidades estatais, bem como a gerência de diversos equipamentos público-estatais - traz como substrato o enfraquecimento da noção de direito social. Por isso, o chamado à participação se dá nos marcos da aceitabilidade prévia dos pontos nevrálgicos do projeto dominante, apressando o que Paoli (2007) chamou de desmanche da política e de seus sujeitos, ao mesmo tempo em que exibe (supostas) qualidades democráticas e vincula os diálogos e negociações aos limites impostos pela ordem em questão. Atuando na condição de pressuposto dado, o projeto dominante atual:

\begin{abstract}
[...] obriga a reivindicação e o diálogo a entrarem nos estreitos espaços daquilo que é permitido acontecer, de modo que as ações participativas ou se conformam com 0 'possível', deixando intactas todas as situações que não cabem nas prioridades governamentais, ou lançam mão de uma expertise técnica que possa prever e realizar desenhos participativos (e escolher as exclusões necessárias) que incluam todos os requisitos obrigatórios para mostrar a ideia de experimento democrático concreto (PAOLI, 2007, p. 236).
\end{abstract}

A relação Estado e organismos na sociedade civil na execução de políticas sociais não se trata de uma retirada do Estado em cumprir seu papel. Cremos estar diante de uma redefinição do seu papel, na medida em que é repassada às entidades apenas a execução cotidiana dessas políticas (NEVES, 2005; MELO, 2011). As diretrizes, metas e modos de operar advêm do bloco no poder (direção majoritária do executivo, do legislativo, bem como ação legitimadora de intelectuais orgânicos coletivos e individuais próximos às suas visões de mundo). Como exemplo, na atuação das OSs no Rio de Janeiro, esse conjunto de questões é definido no contrato de gestão e no plano de trabalho que assinam as entidades com o executivo municipal. Inclusive a lei e o decreto municipal que regulam as relações afirmam a necessidade de percentual de trabalho voluntário e a possibilidade de complementação orçamentária com outras fontes de financiamento. Isso indica que a gestão das políticas segue sendo estatal, no sentido de seguir as orientações e responder à visão de mundo do bloco no poder, do qual o chamado terceiro setor é a ponta de lança da execução dos programas com base no projeto neoliberal (MELO; BOECHAT; ANDRADE, 2016).

\title{
3 PROGRAMA VILAS OLÍMPICAS NA CIDADE DO RIO DE JANEIRO
}

O programa Vilas Olímpicas é uma iniciativa da PMRJ, ainda que sua origem remonte ao programa privado da Escola de Samba Estação Primeira de Mangueira, no final dos anos 1980'. No final da década seguinte, a PMRJ (gestão Luiz Paulo Conde) classificou como "Vilas Olímpicas" os Centros Esportivos Culturais construídos em bairros pobres e/ou favelas na capital fluminense.

Até 2009 existiam as seguintes Vilas Olímpicas na cidade do Rio de Janeiro, com suas datas de inauguração ao lado: 1) Centro Esportivo Miécimo da Silva, 1982, no bairro de Campo Grande; 2) Vila Olímpica da Maré, 2000, no bairro de mesmo nome; 3) Vila Olímpica Carlos Castilho, 2002, no bairro de Ramos (Complexo do Alemão); 4) Vila Olímpica Mestre André, 2002, no bairro de Padre Miguel; 5) Vila Olímpica Clara Nunes, 2002, no bairro de Fazenda Botafogo; 6) Vila Olímpica Jornalista Ary de Carvalho, 2003, no bairro de Vila Kennedy; 7) CIAD Mestre Candeia, 2003 (Centro); 8) Vila Olímpica Oscar Schmidt, 2004, no bairro de Santa Cruz; 9) Vila Olímpica da Gamboa, 2004, no bairro de mesmo nome. Cumpre lembrar que este artigo

1 A partir de 2011, a Vila Olímpica da Mangueira passou a fazer parte do programa da Prefeitura do Rio de Janeiro. Sua gestão ficou a cargo da Organização Social Solazer - clube dos excepcionais vencedor do certame. 
está interessado no período anterior à aprovação da lei das organizações sociais em maio de 2009, já na gestão Eduardo Paes (PMDB). Posteriormente outras unidades foram inauguradas (MELO; BOECHAT; ANDRADE, 2016).

Para implementação de suas ações nas Vilas Olímpicas, a PMRJ valeu-se, em 2000, de convênios com federações esportivas² para gerir cada Vila Olímpica. A Secretaria Municipal de Esporte e Lazer repassava verbas a esses organismos, que contratavam cooperativas para executarem as ações, como mostram o documento do Tribunal de Contas do Município (RIO DE JANEIRO, 2003) e as entrevistas na pesquisa de Melo (2005). A execução desse programa cabia a esses organismos, tendo o grupo da PMRJ/Secretaria Municipal de Esporte e Lazer o controle político mediante a existência da figura da Coordenação Técnica, com cargos de confiança, responsáveis pela coordenação pedagógica do programa, sendo esse o seu elo com o dia a dia dos projetos. Essa forma de ação estatal era a tradução concreta dos princípios emanados na reforma do Estado de 1995 no governo Fernando Henrique Cardoso, do PSDB. A aprovação de legislações federais das Organizações da Sociedade Civil de Interesse Público (OSCIPs) e das Organizações Sociais no final dos anos 1990, mesmo ainda sem uma legislação municipal na cidade maravilhosa, já permitia uma materialização desses elementos em diversos programas. Foi esse o caso do programa Vilas Olímpicas.

O TCM-RJ destacou uma série de questionamentos nos convênios entre a SMEL e organismos na sociedade civil na gestão das Vilas Olímpicas no período 2000-2009. Inicialmente destacamos o apontamento de problemas na relação entre Confederação Brasileira de Triathlon e a SMEL no tocante às Vilas Olímpicas. Segundo o TCM, a referida confederação recebeu $\mathrm{R} \$ 1.808 .154,02$ em três convênios celebrados com a SMEL para implantação de um projeto da modalidade e também atividades esportivas variadas para crianças, jovens, adultos e idosos nas seguintes Vilas Olímpicas: Miécimo da Silva, Clara Nunes (Acari), Santa Cruz e Núcleo Esportivo Parque Royal, Carlos Castilho (Alemão) e Núcleos Esportivos Salgueiro e Tuiuti.

$\mathrm{O}$ documento do TCM-RJ informa que, além do convênio com a federação gestora de unidade, pode ter havido outros convênios com outras federações. Cita, como exemplo, o caso da atuação da Natação no Miécimo da Silva, que é regido pelo Convênio com a Federação de Esportes Aquáticos e não o de Triathlon, como nas outras modalidades desta unidade em questão.

Na Vila Olímpica Clara Nunes (Acari) havia profissionais alocados por três federações por meio de convênios diferentes, segundo Rio de Janeiro-TCM (2003). Como exemplo, professores e estagiários de natação contratados pela Federação de Basquete e professores e estagiários de atletismo contratados pela Federação de Esportes de Praia.

Não obstante, o Tribunal de Contas do Município encontrou notas fiscais emitidas pelas cooperativas sem recolhimento de Imposto sobre serviços (ISS), ou seja, numa ação com a PMRJ encontramos sonegação de impostos. Além disso, havia a existência de guias de recolhimento de INSS sem autenticação bancária, o que poderia indicar não pagamento, apesar da emissão. Inclusive, mesmo com nova solicitação, esse quadro repetiu-se, como mostram as conclusões do documento (RIO DE JANEIRO, 2003, p. 33).

Como as confederações contratam cooperativas para executarem os convênios, a SMEL pagou assim taxas de administração duas vezes: primeiro às confederações e depois às

2 A Vila Olímpica da Maré (VOM) foi a primeira a ser administrada por uma ONG (União Esportiva Vila Olímpica da Maré-UEVOM - formada por moradores da Maré, membros de outras ONGs como VIVA Rio). Entretanto, a VOM conviveu por algum tempo com a truncada relação entre PMRJ x UEVOM e PMRJ x federações, quanto a seu funcionamento. Tal processo está analisado e descrito em detalhes em MELO (2005). 
cooperativas, resultando em gastos extras e desnecessários à administração pública, conforme está expresso no documento do Tribunal de Contas do Município do Rio de Janeiro (RIO DE JANEIRO, 2003, p. 4).

Esse conjunto de questões na relação nos primórdios das Vilas Olímpicas em relação à atuação das federações tem como exemplo a arguição do representante da Federação de Triathlon pelo TCM em 2003. Inicialmente afirmou não ser representante oficial, mas "[...] responsável pela solução de problemas atrativos e de recebimento de documentos" (RIO DE JANEIRO, 2003, p. 32). O documento do TCM afirma não ter ficado evidenciado qual o papel de fato realizado pela referida Federação nas Vilas Olímpicas e Núcleos Esportivos.

O Tribunal de Contas do Município também analisou as relações entre a SMEL e Federação de Esportes Aquáticos do Rio de Janeiro (FARJ). Esta possuía convênios com a SMEL para atuar nas seguintes Vilas: Centro Esportivo Miécimo da Silva (R\$ 2.229.531,84, com vigência de 01-01-2003 a 31-01-2005, embora só tenham sido de fato liquidados $R \$$ 1.207.663,08); Clara Nunes (R\$516.104,19, com vigência de 01-04-2003 a 31-12-2004, embora só tenham sido de fato liquidados $\mathrm{R} \$ 344.069,16)$; Carlos Castilho ( $\mathrm{R} \$ 516.104,19$, com vigência de 01-04-2003 a 31-12-2004, embora só tenham sido de fato liquidados $R$ \$344.069,16); Mestre André ( $\mathrm{R} \$ 619.382,16$, com vigência de 30-08-2002 a 30-08-2004, embora só tenham sido de fato liquidados $R \$ 464.536,62)$. Salta aos olhos a execução exatamente do mesmo valor inclusive os centavos - em duas unidades diferentes (RIO DE JANEIRO, 2004, p. 5).

Já a Federação de Basquetebol do Estado do Rio de Janeiro (FBERJ) possuía convênio com a SMEL para desempenhar atividades nas seguintes Vilas: Centro Esportivo Miécimo da Silva ( $R$ \$ 1.103.312,88, com vigência de 01-02-2003 a 31-01-2005, embora só tenham sido de fato liquidados $R \$ 597.627,81$ ); Clara Nunes ( $R$ \$282.270,66, com vigência de 01-042003 a 31-12-2004, embora só tenham sido de fato liquidados $R \$ 188.180,44) ;$ Carlos Castilho ( $R$ \$ 282.270,66, com vigência de 01-04-2003 a 31-12-2004, embora só tenham sido de fato liquidados $R \$ 188.180,44$; Mestre André ( $R \$ 282.761,28$, com vigência de 30-08-2002 a 3008-2004, embora só tenham sido de fato liquidados $\mathrm{R} \$ 212.070,96$ ) (RIO DE JANEIRO, 2004, p. 5). Novamente a exatidão de valores executados em dois contratos de unidades diversas chama atenção. A despeito do recebimento de recursos, foi comum atraso de salário na relação com os então cooperados, como mostra o referido documento do TCM.

O documento do TCM mostra que no caso do Centro Miécimo da Silva, além das Federações de Esportes Aquáticos (FARJ) e de Basquete (FBERJ), outras federações também atuavam nessa unidade como as de Vôlei, Judô, Futebol Society, Esportes de Praia e a Associação Regional de Deficientes Físicos (ARDEM). No caso dessas últimas citadas não havia qualquer convênio formal ou contrato (RIO DE JANEIRO, 2004, p. 20). Como essas entidades fizeram para pagar seus funcionários já que não havia convênio formal com município? 0 TCM foi informado ter havido autorização expressa da SMEL para contratação emergencial por dois meses dessas entidades a partir de junho de 2003 e que esse procedimento passou a repetir-se sucessivamente ao menos até a edição do documento em questão do TCM, em abril de 2004. Isso gerou uma série de empenhos e pagamentos mensais às federações (RIO DE JANEIRO, 2004).

Valer-se de cooperativas e federações esportivas para contratação de pessoal para atuar nas Vilas Olímpicas foi extremamente funcional ao bloco César Maia no poder. O Relatório de Inspeção Ordinária-SMEL 4 IGE (RIO DE JANEIRO, 2004, p.7) mostra a 
alegação do coordenador do Miécimo da Silva de que a incompatibilidade entre o número de funcionários cooperativados e o número efetivo atuando naquela unidade deveu-se ao fato de 35 trabalhadores estarem atuando na parte administrativa na sede da SMEL-PMRJ recebendo seus vencimentos a partir de convênio Federação x SMEL. Esse processo também se deu no convênio entre a Federação de Basquete e a SMEL para atuação do Miécimo da Silva, com uma diferença de 18 trabalhadores dentre a relação de cooperados e os que de fato lá atuavam (RIO DE JANEIRO, 2004, p. 15). A existência desse procedimento em dois convênios indica ter sido praxe o deslocamento de trabalhadores pagos para atuarem nas Vilas para a sede da SMEL em funções administrativas. Esse fato é apontado pelo TCM como praxe, já que foram encontrados trabalhadores em todas as relações das federações que deveriam atuar, mas que não o faziam (descontando os que supostamente estariam trabalhando na SMEL). Exatamente quarenta e nove trabalhadores simplesmente não foram encontrados nem nos registros de ponto do Miécimo da Silva e nem na SMEL, implicando nitidamente severos problemas legais. Não por acaso, o TCM instou a SMEL a explicar o que chamou de discrepância (RIO DE JANEIRO, 2004, p.23). Ainda que o relatório não afirme de forma enfática, há uma nítida suspeita de funcionários-fantasma ou em graves desvios de função, recebendo pelas federações e desempenhando funções outras, inclusive privadas.

Atendo-se exclusivamente aos documentos e aos fatos relatados, fica expresso um desvio de finalidade e descumprimento contratual por parte do próprio bloco no poder, que pagava o trabalhador para atuar na Vila, mas exigia seu deslocamento (supostamente) para atuação administrativa na sede da Secretaria Municipal de Esporte e Lazer. Poderia ter havido alguma forma de reclamação formal da federação ou cooperativa em função do enfraquecimento financeiro da instituição de pagar um profissional a partir do montante recebido no convênio e ele não atuar no programa sob sua chancela. Mas certamente o desequilíbrio de forças entre o contratante (PMRJ-SMEL) e a contratada (federação) não abriu margens a nenhuma reivindicação ou denúncia.

Posteriormente o TCM (RIO DE JANEIRO, 2004) inquiriu à SMEL a relação de pessoal das cooperativas que atuavam em sua sede. Chegando ao número de 86 trabalhadores, ficou comprovada a ampla utilização dos mecanismos de convênios para outros fins para prover de pessoal a administração da Secretaria de Esporte e Lazer.

Segundo documento do TCM (RIO DE JANEIRO, 2004), alguns cooperados relatam que estavam atuando no Centro Esportivo Miécimo da Silva desde 1998 em cooperativas, ou seja, antes da existência do programa Vilas Olímpicas. Mesmo com as mudanças dos convênios com o Município seguiam atuando sob nova cooperativa. A ordem cronológica de cooperativas, no caso do Miécimo da Silva foi: $1^{\underline{a}}$ Cooperativa Nacional Multidisciplinar de Serviços (1998-2000); 2 ${ }^{\text {a }}$ Cooperativa Aliança (2000-2003); 3르 Cooperativa Labor Rio (20032005). Segundo o TCM esta última cooperativa chegou a contratar trabalhadores para a maioria das Vilas Olímpicas do Município no período em tela (RIO DE JANEIRO, 2004).

Também a Vila Olímpica Clara Nunes (Acari) inicia seus trabalhos a partir de convênios da SMEL com a Federação de Esportes Aquáticos do Rio de Janeiro (FARJ) e a Federação de Basquetebol do Rio de Janeiro (FBERJ). Essas entidades contratavam cooperativas de trabalhadores para que professores, estagiários e pessoal administrativo desempenhassem as funções propriamente ditas dessa política pública. A cooperativa contratada era a Cooperativa Múltipla de Prestação de Serviços Ltda. (COOMPS). Também foi constante a ocorrência de 
trabalhadores registrados como atuando na referida Vila Olímpica e na verdade realizarem atividades no âmbito da SMEL (RIO DE JANEIRO, 2004).

O TCM mostra no documento que a condição de cooperativado era inexistente, já que não havia assembleias gerais de tomada de decisões, nem retorno de sobras líquidas de recursos dos contratos aos cooperados no caso das cooperativas COOMPS e Labor Rio (RIO DE JANEIRO, 2004, p.49). Segundo o relatório do TCM, na verdade os trabalhadores "[...] são empregados e não cooperados, o que poderia gerar para o município uma responsabilidade subsidiária em decorrência de demandas judiciais pleiteando direitos trabalhistas previstos na CLT" (RIO DE JANEIRO, 2004, p. 41). Isso levou o TCM ao forte questionamento desses mecanismos de precarização das políticas sociais.

O modelo de gestão das Vilas Olímpicas (e quiçá outros equipamentos públicos da PMRJ) de que se valeu o bloco no poder César Maia passou a ser duramente questionado a partir de 2005. Tanto o TCM como Ministério Público do Trabalho (MPT) realizaram, nos limites de suas atribuições, fortes críticas à relação entre Secretaria de Esportes x federações esportivas $X$ cooperativas na execução do programa Vilas Olímpicas. Mais especificamente 0 MPT entrou com ação civil pública (Processo n. 00802-2005-004-01-00-2) para:

[...] coibir a celebração de instrumentos contratuais com as federações, confederações e cooperativas esportivas, bem como questionando a legalidade das contratações de trabalhadores sem concurso público e dos contratos de prestação de serviços firmados com tais entidades em relação a sua atividade-fim (RIO DE JANEIRO, 2005, p.3-4).

Nessa peça do MPT há depoimentos que demonstram não ter ocorrido seleção de trabalhadores e sim indicações "apadrinhadas", para usar expressão que consta no documento do TCM (RIO DE JANEIRO, 2005, p.4). O TCM chamou a relação SMEL x federações X cooperativas $X$ trabalhadores de "quarteirização" (RIO DE JANEIRO, 2005), implicando a distorção de valores em relação a custos de projetos, valores recebidos e valores pagos aos trabalhadores. Até mesmo a inexistência de relação jurídica SMEL $X$ cooperativa pode ser uma barreira na proteção à Administração Pública no caso de maus serviços prestados pelas cooperativas.

Inexistem relações cooperadas e sim empregos sem vínculos. Esse modus operandi como intensificador da exploração era mais agravado pelos frágeis vínculos dos trabalhadores com as cooperativas e federações. O relatório do TCM fornece um exemplo disso quando menciona o fato dos trabalhadores que eram vinculados à Federação de Judô do Rio de Janeiro terem seguido atuando na Vila Olímpica Mestre André em 2005 mesmo com contrato com a SMEL rescindido. $O$ documento fala que os trabalhadores seguiam "[...] prestando serviços na condição de voluntários na Vila Olímpica Mestre André, pois tinham esperanças de serem efetivados futuramente" (RIO DE JANEIRO, 2005, p. 21), ainda que não houvesse sequer uma declaração de trabalho voluntário. Tal fato também foi relatado no mesmo documento do TCM em relação à Federação de Esportes de Praia, que atuava na Vila Olímpica Clara Nunes (Acari), inclusive no tocante à esperança de retornarem futuramente (RIO DE JANEIRO, 2005, p. 27).

Ao fim o MPT indicou o cancelamento imediato, sob pena de multa diária, de qualquer convênio, termos aditivos, celebrados com federações esportivas e cooperativas para contratação de força de trabalho; convocação de pessoal aprovado em concurso público para atuarem nas atividades fins (atendimento à população no direito social em tela - esporte e 
lazer); afastamento de trabalhadores cooperados que estavam atuando na sede da SMEL; além dessas recomendações, outras por parte do MPT (RIO DE JANEIRO, 2005) marcaram o início do fim dessa forma de executar o programa Vila Olímpica na cidade do Rio de Janeiro. Isso indicava não somente ao bloco no poder em questão, mas também a seus adversários do mesmo campo, que a forma de gerir os equipamentos públicos demandaria alterações. Não por acaso, o documento do TCM termina essa sessão com o anúncio de que o então novo Secretário Municipal de Esporte, Gustavo Cintra, tinha como meta:

\begin{abstract}
[...] a substituição do modelo de contratação por outro que respeite os direitos trabalhistas e que esteja em consonância com as normas administrativas e que está acelerando os procedimentos para recrutamento de servidores municipais para atuarem na SMEL, tanto no nível central, como nas Vilas Olímpicas e demais equipamentos [...] (RIO DE JANEIRO, 2005, p. 8).
\end{abstract}

A partir dessa posição do TCM acerca das intenções do então novo secretário, encontramos um anúncio do modelo das OSs implementado pelo bloco no poder PMDB-PT a partir de 2009, com a aprovação da Lei 5026-2009 (das OSs) e ao mesmo tempo uma reconhecida simpatia e boa vontade do próprio TCM para com essa alternativa de gestão. A longa e partida citação faz-se necessária para não deixar de apontar a totalidade da posição (política) do TCM. Esse documento (RIO DE JANEIRO, 2005, p. 8) afirma constatar "[...] esforço empreendido para substituição de federações esportivas e cooperativas por um novo modelo de gestão, a ser empreendido pela contratação de entidades sem fins lucrativas formadas por instituições superiores, tais como: CIESZO, PUC-RIO [...]". E o próprio documento do TCM (RIO DE JANEIRO, 2005, p. 36) mostrou que a contratação do Conselho de Instituições de Ensino Superior da Zona Oeste (CIESZO) não impediu que as cooperativas e federações seguissem atuando na "quarteirização" da contratação de trabalhadores. Ou seja, a questão é que esse modelo era política do bloco no poder e só foi questionado em função da intervenção do Ministério Público do Trabalho.

Menos do que análise da posição de simpatia do TCM para com a contratação de organizações (supostamente) sem fins de lucro, salta aos olhos a ideia de que tal mecanismo sanaria a precarização observada no tempo das federações/cooperativas.

O ano de 2005 não marcou apenas o primeiro ano do terceiro mandato de Cesar Maia à frente da Prefeitura do Rio de Janeiro. Também representou o momento que o mecanismo de implementar políticas sociais via cooperativas não foi mais tolerado pelo Ministério Público do Trabalho. A solução foi valer-se de outras entidades (supostamente) sem fins lucrativos, sobretudo, universidades privadas.

A Vila Olímpica da Gamboa foi administrada inicialmente pela Pontifícia Universidade Católica, por meio de entidade (supostamente) sem fins de lucro chamada Faculdades Católicas. É esta entidade que realizou contratos em 2005 (69/2005) e 2006 (n. 29/2006) com a SMELPMRJ com vigências de 26-10-2005 a 25-04-2006 e 26-04-2006 a 25-04-2007. O TCM é enfático em destacar não ter havido "processo seletivo", contrariando a Resolução 11/2006 da própria SMEL de 09-06-2006 e publicada em Diário Oficial no dia seguinte (RIO DE JANEIRO, 2006).

O TCM destacou a irregularidade trabalhista cometida pela PUC-RIO de só assinar carteira de trabalho após três meses de efetivo exercício, implicando prejuízo ao trabalhador de diversas ordens. Para tal, foi listada uma série de trabalhadores em situação de precariedade (RIO DE JANEIRO, 2006). Também cabe registrar que a precarização também se dava no 
tocante às condições de trabalho. A equipe de limpeza e conservação atuava com chinelos e sandálias e não com equipamentos de segurança garantidos em contratos.

O documento do TCM traz a informação da inclusão de taxa de administração de 10\% cobrada pela entidade Faculdades Católicas (PUC-RIO) "a título de filantropia [...] sobre o valor bruto do cargo" (RIO DE JANEIRO, 2006, p. 16). Mesmo não ficando claro o que signifique "valor bruto do cargo" dá a entender que uma parte do contrato era apropriada pela entidade supostamente como taxa de administração. Um dado trazido pelo TCM que chamou a atenção foi o acréscimo mensal de 65,4\% do contrato de seis meses de 2005 (69/2005) para o contrato anual de 2006 (29/2006) (RIO DE JANEIRO, 2006, p. 17). Superando em muito qualquer índice inflacionário e sem encontrar justificativa na natureza das atividades desempenhadas, que poderia ser justificada mediante apresentação de dados novos que mostrassem novos determinantes no segundo contrato que inexistiam no primeiro, isso já botava em questão um dos argumentos clássicos dos apologistas do chamado terceiro setor na execução das políticas sociais, que seria seu (suposto) menor custo em relação ao modelo estatal. Isso é contradito pelo TCM, embora falte o elemento comparativo no caso das políticas de esportes, visto não haver equipamentos que sejam geridos diretamente pela PMRJ.

Algumas ONGs que posteriormente foram qualificadas como OSs (MELO; BOECHAT; ANDRADE, 2016) e passaram a gerir equipamentos e executar programas municipais de esporte e lazer após a aprovação da lei em 2009 já o faziam antes dessa legislação. Podemos citar a ONG CEACA-VILA. Tal ONG já possuía relações orgânicas com a SMEL no governo César Maia (2001-2008). O programa MEL I da SMEL foi gerido pelo CEACA VILA de 2007 a 2009 mediante formas de convênios/contratos. No primeiro caso, por meio do Convênio 17/07, que esteve vigente de 01-04-2007 a 25-03-2008. Posteriormente, um novo convênio (20/08) no valor de $\mathrm{R} \$ 5.800 .000,00$ foi assinado pelo período de 26-03-2008 a 25-03-2009 (RIO DE JANEIRO, 2008). Em outro momento do documento é revelado que a ONG CEACA VILA já executa o Programa MEL desde 2005, por meio do convênio FRE 08/2005 (RIO DE JANEIRO, 2008, p. 8). Mais adiante no mesmo documento, há a informação que esta entidade está envolvida na execução do programa desde junho de 2003, por meio do convênio FRE 17-2003 (p. 20). O TCM também traz a informação, sem precisar em qual, que a ONG CEACA VILA executava algum programa na Secretaria Municipal de Assistência Social (RIO DE JANEIRO, 2008, p. 10).

Uma conhecida alegação acerca dos benefícios da execução das políticas sociais pelos organismos privados sem fins de lucro geralmente repousa numa suposta maior eficiência e eficácia. Consultando os documentos da Reforma do Estado no Brasil (BRASIL, 1995) e seus maiores apologetas (IOSCHPE, 1996), são constantes menções a uma suposta melhor gestão por parte dos organismos privados em relação a órgãos estatais. Isso estaria relacionado a algo quase intrínseco à gestão estatal como perdulária e descompromissada. Contudo, a análise de diversos casos concretos revela dados diferentes. Como exemplo, trazemos as compras de materiais esportivos realizadas pela entidade CEACA VILA no âmbito da gestão do programa MEL 1 da SMEL-RJ. Segundo o TCM, na compra de bolas de futebol society houve uma variação média de $201 \%$ em relação ao preço obtido no pregão da própria SMEL; quanto à rede de futebol de campo, essa variação entre preço obtido pela SMEL x preço CEACA VILA foi de 96\%; apenas num produto houve uma diferença desprezível de preço (12\% na rede futsal) (RIO DE JANEIRO, 2008). Em nenhum produto manifestou-se a tão propalada 
eficiência de gestão refletida nos preços de materiais necessários para a execução cotidiana dessa política. Inclusive, o TCM localizou diferença de preços do mesmo material (bola de futebol de campo) da ordem de $200 \%$ (de $R \$ 19,90$ a $R \$ 60$ ) num curto espaço de tempo. Obviamente, é impossível fazer qualquer ilação ou afirmação das razões dessa diferença de preço desfavorável ao fundo público, mas o fato é estarmos diante de dados incontestes que põem em xeque a suposta eficácia e eficiência.

A ênfase constante que 0 universo das ditas ONGs exalava em serem não governamentais estava radicada num suposto símbolo de virtude justamente por esse fato (FONTES, 2010), ainda que isso futuramente tenha sido convertido em suposto elemento diferenciador em face de órgãos governamentais na execução de políticas sociais. Valendose do fato real de que o desenvolvimento capitalista brasileiro (e latino-americano, malgrado a diferença interna entre as diversas formações sociais) fez com que a ação estatal voltada à proteção social e acesso a direitos por parte dos setores subalternos seja profundamente deficitária, ineficiente e precária, o projeto neoliberal encontrou nas chamadas ONGs parceiros ideais na privatização da ação estatal em diversas frentes. Se certamente o Estado brasileiro merecia e merece sofrer duríssimas críticas, isso não pode servir para esconder o estreito vínculo que há entre seu modus operandi e a consecução de interesses burgueses nessa forma, alcance e modalidade de atuação estatal em diversos campos. Como afirma Virginia Fontes (2010, p. 267), tal postura obstaculizava a "[...] coesão necessária para realização de lutas universalizantes, cuja viabilidade depende fortemente de uma estreita correlação entre os diferentes aparelhos privados de contra-hegemonia". Justamente esse contexto que produziu uma naturalização da atuação de ONGs e federações na execução do programa Vilas Olímpicas, malgrado suas documentadas contradições e precariedades em diversos campos.

A noção de trabalho social transforma-se em novas portas da exploração, arbitrariedade, do clientelismo e assistencialismo, ainda que travestidos de prestação de benfeitorias a moradores de favelas. Houve, nas Vilas Olímpicas, a conjugação da identidade de ONG ou federação esportiva que realiza trabalho social ao lado de práticas empresariais com vistas a extrair mais valia dos trabalhadores e intensificar o lucro. O quadro traçado por Cibele Rizek (2010, p. 233) é revelador das possibilidades da dita inclusão social na sociedade capitalista em tempos de finança mundializada, havendo um "[...] espectro de possibilidades resultantes dessa perversa combinação entre situação urbana, crise do emprego, dificuldades e precarização de toda ordem [...]". Assim, os trabalhadores disponíveis nos bairros mais pobres e precários tornam-se motores de uma lógica acumulação de capital travestida de ação social edificante para seus promotores. É a exploração da força de trabalho com a face da chamada inclusão social. A dita reinserção profissional precária, obstando a garantia de qualquer direito em nome da noção de "melhor isso que nada", implica o atamento das mãos "[...] pelas cordas das mediações morais dos empreendimentos sociais, pelos vínculos embaralhados do combate e da assimilação da pobreza, nas tessituras das novas formas de produção entrelaçadas aos territórios híbridos das bordas da cidade" (RIZEK, 2010, p. 233).

\section{CONCLUSÕES}

A partir dos dados concretos trazidos neste texto fica expresso que os mecanismos de privatização trazidos pelo projeto neoliberal - expressamente a delegação da execução das políticas sociais por entes privados, sejam empresas ou organismos na sociedade civil - estão 
longe de representar a afirmação de direitos sociais. O que tem sido apontado por analistas há tempos (FONTES, 2010; NEVES, 2005; PAOLI, 2007; MELO, 2011) ganha concretude. Não se trata de objeção apenas conceitual às formas de privatização. Trata-se da clareza de que não é possível haver conciliação entre interesses privados e interesses coletivos. Quando a lógica do lucro movimenta a ação humana em qualquer campo, o interesse coletivo é arranhado. Não obstante, não devemos esquecer que, no caso concreto analisado, há fortes possibilidades dessa privatização ser elemento para pessoalização da ação estatal, bem como a abertura de redes clientelistas a partir das ações de entidades (apenas supostamente) sem fins de lucro. Tanto no atendimento a seus direitos como cidadãos, como na condição de trabalhadores desses programas, os trabalhadores e trabalhadoras são duplamente explorados.

A ênfase glorificadora de um universo "privado, porém público", expressão consagrada no título de um livro homônimo de Rubem Cesar Fernandes (1996), um dos expoentes da ONG VIVA RIO e militante conhecido do campo das ONGs, indica uma expressa vulgarização e reversão semântica do sentido de "público" e "privado". Como mostram Virgínia Fontes (2010) e Lúcia Neves (2005), menos do que indicar uma diminuição ou retirada do Estado, vislumbrouse uma ampliação da aparelhagem estatal no Brasil, tanto no sentido gramsciano como em termos fáticos, em que o poder de pressão reivindicativa das classes subalternas foi subtraído nessa ampliação.

Trouxemos debates e dados anteriores à lei municipal das OSs no Rio de Janeiro (lei 5026/2009) porque a naturalização da privatização da ação estatal no tocante às suas políticas sociais deu mais um avanço com essa legislação. Contudo, tal processo não é isento de contradições e desdobramentos para os sujeitos de direitos.

\section{REFERÊNCIAS}

BRASIL. Presidência da República. Câmara de Reforma do Estado. Plano Diretor da Reforma do Aparelho do Estado. Brasília, DF: Presidência da República do Brasil, 1995.

FERNANDES, Rubem César. Privado, porém Público: o terceiro setor na América Latina. Rio de Janeiro: Relume Dumará; 1996.

FONTES, Virgínia. O Brasil e o capital-imperialismo. 2. ed. Rio de Janeiro: EPSJV/Editora UFRJ, 2010.

IOSCHPE, Evelyn Berg (Org.). Terceiro Setor e Desenvolvimento Social Sustentado. São Paulo: GIFE/Paz e Terra, 1996.

MELO, Marcelo Paula de. Esporte e juventude pobre: políticas públicas de lazer na Vila Olímpica da Maré, Campinas, SP: Autores Associados, 2005.

MELO, Marcelo Paula de. Esporte e dominação burguesa no século XXI: a agenda dos Organismos Internacionais e sua incidência nas políticas de esportes no Brasil de hoje. 2011. 354f. Tese (Doutorado em Serviço Social) - Rio de Janeiro: Universidade Federal do Rio de Janeiro, 2011. 
MELO, Marcelo Paula de. As FASFILs de Cultura e Recreação no Censo IPEA/IBGE 2005: questões para o lazer, esporte e educação física. Movimento, v. 21, n. 4, p. 999 -1010, out./dez. de 2015 .

MELO, Marcelo Paula de; BOECHAT, Marina; ANDRADE, Gustavo Martins. As Vilas Olímpicas na cidade do Rio de Janeiro e as chamadas Organizações Sociais: o neoliberalismo em campo. Revista em pauta (UERJ), v. 14, n. 38, p. 259-279, 2016.

NEVES, Lucia Maria W. (Org.). A Nova Pedagogia da Hegemonia: estratégias da burguesia brasileira para educar o consenso na atualidade. São Paulo: Xamã, 2005.

PAOLI, Maria Celia. O mundo indistinto: sobre gestão, violência e política. In: OLIVEIRA, Francisco; RIZEK, Cibele Saliba (Orgs.). A Era da Indeterminação. São Paulo: Boitempo, 2007. p. 221-256.

RIO DE JANEIRO (MUNICÍPIO). TRIBUNAL DE CONTAS DO MUNICÍPIO. Processo $\mathbf{n}$. 40/4337/2003, 22 jul. 2003. Rio de Janeiro, 2003.

RIO DE JANEIRO (MUNICÍPIO): TRIBUNAL DE CONTAS DO MUNICÍPIO. SECRETARIA DE CONTROLE EXTERNO. 4 IGE Relatório de Inspeção Ordinária- SMEL. Rio de Janeiro, 2004.

RIO DE JANEIRO (MUNICÍPIO): TRIBUNAL DE CONTAS DO MUNICÍPIO. SECRETARIA DE CONTROLE EXTERNO. 4 IGE Relatório de Inspeção Ordinária- SMEL 2005. Maio a outubro 2005. Rio de Janeiro, 2005.

RIO DE JANEIRO (MUNICÍPIO). TRIBUNAL DE CONTAS DO MUNICÍPIO. SECRETARIA DE CONTROLE EXTERNO. 4 IGE Relatório de Inspeção Ordinária- SMEL Outubro 2006. Rio de Janeiro, 2006.

RIO DE JANEIRO (MUNICÍPIO). TRIBUNAL DE CONTAS DO MUNICÍPIO. SECRETARIA DE CONTROLE EXTERNO. Auditoria operacional no programa MEL I. Rio de Janeiro, 2008.

RIZEK, Cibele Saliba. Verde, amarelo, azul e branco: o fetiche de uma mercadoria ou seu segredo. In: OLIVEIRA, Francisco; BRAGA, Ruy; RIZEK, Cibele (Orgs.). Hegemonia às avessas. São Paulo: Boitempo, 2010. p. 215-235. 
